\title{
A scholarly discipline comes of age
}

\section{David P Stevens}

How do you know when a scholarly discipline comes of age? For example, just two or three decades ago, the field of health services research was an infant, with little attention paid to it in the halls of academe. Now, it is a mainstream discipline where a scholar can make his or her academic bones with little fear of risking a career at the margins of scholarship.

Many readers of QSHC who have toiled in the scholarly vineyards of healthcare improvement and patient safety certainly consider these fields mainstream. Nevertheless, many in healthcare, particularly academe, are just beginning to acknowledge the centrality of these fields. I propose that scholarship in these fields is indeed close to full-blown adulthood. What are the signs? Here are five.

\section{LENGTHENING QUEUE OF EXCELLENT ACCEPTED OSHC PAPERS}

There was a time-just 5 years ago-when the editors of OSHC had to scramble to find sufficient numbers of scholarly papers to fill 80 pages for publication every 2 months. Now, in spite of an ever-higher bar for acceptance of scholarly papers, the queue of accepted papers awaiting publication in the print journal has lengthened to an intolerable duration-over a year.

The good news, on the other hand, is that, as of 2010, QSHC will publish accepted papers Online First, a BMJ service that allows authors to see their papers available to readers online soon after formal acceptance, usually within the time required to proof and post PDF versions of their accepted papers. As a result, the queue will be eliminated, and in the future, accepted papers will be posted soon after making their way through the review process.

\section{EXPANDING BREADTH OF SCHOLARLY QUALITY AND SAFETY JOURNALS}

There is a growing number of scholarly journals such as QSHC that are specifically focused on implementation of improvement and patient safety strate-

Correspondence to Dr David P Stevens, Quality Literature Program, Dartmouth Institute for Health Policy and Clinical Care, 30 Lafayette Street, Lebanon, NH 03766, USA; david.p.stevens@dartmouth.edu gies. Now, new journals in wider fields of health and healthcare are coming to the fore, reflecting a broadening commitment to improvement and safety. Examples include Circulation: Cardiovascular Quality and Outcomes, a discipline-focused journal with a strong focus on improvement in cardiovascular diseases. ${ }^{1}$ Other speciality journals such as Annals of Internal Medicine $^{2}$ and Journal of General Internal Medicine $^{3}$ are examples of general clinical journals that have committed pages, sections or special issues specifically to improvement and safety.

\section{CHANGING POLICY BY ACCREDITATION AND CERTIFICATION AGENCIES}

In the USA, the Accreditation Council on Graduate Medical Education and the American Board of Medical Specialities have advanced practice-based learning and improvement and systems knowledge as two of the six General Competencies for training programme accreditation and speciality recertification respectively. ${ }^{4}$ This policy shift adds strong pressure on development of the scholarship that underlies these elements of medical practice. A new journal, the Journal of Graduate Medical Education devotes specific pages to practice-based improvement and systems knowledge. ${ }^{5}$ While these reports often focus on education, they are increasingly linked to the improved clinical outcomes that result from improvement education. This change in accreditation and certification policy has served to contribute to rigorous and innovative scholarship. ${ }^{6}$

\section{GEOGRAPHIC SPREAD OF SCHOLARSHIP}

This issue of QSHC features two reports initiated by the WHO Alliance for Patient Safety that report the state of scholarship in broad reaches of the world. Jha and colleagues summarise the process that defined 23 major topics and was principally based on studies in developed nations. The report also puts emphasis on addressing the burden of unsafe care that falls on populations in developing regions of the world. ${ }^{7}$ Perscarpio and colleagues provide a deeper examination of reports that come from the developing nations. ${ }^{8}$

\section{EXPLORING THE EPISTEMOLOGY OF IMPROVEMENT AND SAFETY}

How does this move from scholarly activity to the transformation of healthcare? Knowing how we know something-its epistemology-is central to understanding the path forward in scholarship in an emerging field. ${ }^{9} 10$ As the scholarly literature expands in patient safety and healthcare improvement, ${ }^{11} 12$ it is every scholar's intention that the new knowledge will achieve ever-greater improvement for the health and healthcare of patients. Above all, that intention is probably the most reassuring confirmation that these scholarly disciplines are coming of age.

Competing interests The author is Editor-in-Chief of Quality and Safety in Health Care.

Qual Saf Health Care 2010;19:2.

doi:10.1136/qshc.2010.040352

\section{REFERENCES}

1. Krumholz HM. Cardiovascular quality and outcomes: Scholarship to improve health and health care for patients and populations. Circ Cardiovasc Qual Outcomes 2008;1:1-3.

2. Wachter RM, Shojania KG, Saint S, et al. Learning from our mistakes: Quality grand rounds, a new casebased series on medical errors and patient safety. Ann Intern Med 2002;136:850-2.

3. Bowen JL, Cook DA, Gerrity M, et al. Navigating the JGIM special issue on medical education. J Gen Int Med 2008;23:899-902.

4. Batalden $\mathbf{P}$, Leach D, Swing S, et al. Genera competencies and accreditation in graduate medical education. Health Aff (Millwood) 2002:21:103-11.

5. Batalden PB, Leach DC. Sharpening the focus on systems-based practice. J Grad Med Education 2009;1:1-3.

6. Batalden PB, Davidoff F. Teaching quality improvement the devil is in the details. JAMA 2007;298:1059-61.

7. Jha AK, Prasopa-Plaizier N, Larizgoita l, et al. Patient safety research: an overview of the global evidence. Qual Saf Health Care 2010;19.

8. Percarpio KB, Duelvel MA, Lee PW, et al. Measures of patient safety in developing and emerging countries: a review of the literature. Qual Saf Health Care 2010;19

9. Brown C, Hofer T, Johal A, et al. An epistemology of patient safety research: A framework for study design and interpretation. Part 4. One size does not fit all. Qual Saf Health Care 2008;17:178-81.

10. Davidoff F, Batalden P, Stevens D, et al. Mooney S and the SQUIRE development group. Publication guidelines for quality improvement in health care: evolution of the SOUIRE project. Qual Saf Health Care 2008;17:i3-9.

11. Stelfox HT, Palmisani S, Scurlock C, et al. The 'To Err is Human' report and the patient safety literature. Oual Saf Health Care 2006;15:174-8

12. Rubenstein LV, Hempel S, Farmer MM, et al. Finding order in heterogenrity: types of quality-improvement intervention publications. Qual Saf Health Care 2008;17:403-8 